Dossiê

\title{
Comunidade: mito e ideologia política na era da diversidade cultural
}

Maria Celeste Mira'

Resumo: O objetivo do texto é mostrar, por meio de trabalho etnográfico próprio, pesquisas recentes sobre questões correlatas e fontes bibliográficas, como o conceito de "comunidade", após sua retomada nas práticas políticas e culturais, no fim do Século XX, apresenta dupla face. De um lado, como em outros períodos da História, tem um aspecto romântico, utópico e mesmo mítico; de outro, constitui-se em ideologia política conservadora, em categoria essencial à percepção do espaço social na era da diversidade cultural, capaz de operacionalizar relações de poder e de exploração do trabalho das classes populares.

Palavras-chave: comunidade; diversidade cultural; cultura popular tradicional; ONGs.

\section{Community: myth and political ideology in the cultural diversity era}

Abstract: The aim of the text is to show, through own ethnographic work, recent research on related issues and bibliographical sources about the concept of "community" that its revival, in the end of the twentieth century, has a double face. On the one hand, as in other periods of history, it has a romantic, utopian and even mythical aspect; on the other, it constitutes a conservative political ideology, an essential category to the perception of social space in the cultural

1 Programa de Estudos Pós-Graduados em Ciências Sociais da Pontifícia Universidade Católica de São Paulo (PUC-SP) - São Paulo - Brasil - celestemira@gmail.com. 
diversity era, able of operationalizing power relations and exploitation of the work of the popular classes.

Keywords: community; cultural diversity; traditional popular culture; NGOs.

\section{Introduç̃̃ó}

Poucas palavras adquiriram, na virada para o terceiro milênio, uso tão abrangente e ambíguo quanto "comunidade". No trabalho de campo realizado na cidade de São Paulo, entre 2003 e 2013, sobre a atuação dos "mediadores da cultura popular", chamou a atenção, logo de início, que os artistas ou grupos considerados populares e tradicionais fossem chamados por eles de "comunidades". O termo aparecia completamente naturalizado entre os grupos de jovens de classe média envolvidos, desde os anos 1990, com práticas de pesquisa e recriação de "cultura popular" (Mira, 2016). Falava-se na Comunidade dos Arturos, na Comunidade do Jongo de Tamandaré e em várias outras. Era mais do que evidente no discurso dos agentes a idealização da "vida comunitária", fruto da admiração, ainda que verdadeira, de uma suposta "felicidade na simplicidade" do mundo popular.

Uma das formulações que articula esse universo de ações e representações é o discurso da diversidade cultural. Assim como no caso dos conceitos de "cultura popular" e "tradição", entre outros, a reativação da noção de "comunidade", na virada para o terceiro milênio, se vincula à consagração da ideia de "diversidade", em particular, à de "diversidade cultural". Por sua vez, grande parte do sucesso atual da gramática discursiva da diversidade deve-se à atuação da Unesco (Mattelart, 2005; Pitombo, 2011; Alves, 2011). Ainda sob o impacto da II Guerra Mundial, esse influente órgão da ONU é criado com a tarefa específica de combater a intolerância entre os povos e proteger as diferentes formas de expressão cultural. Estava plantada a semente do discurso triunfante da diversidade cultural, alimentado não apenas pelos sucessivos documentos produzidos ao longo da segunda metade do Século XX pela Unesco, como também pelos movimentos identitários dos anos 1960 em diante, pelas imigrações, pelas teorias multiculturalistas, pela política da exceção cultural (Nicolau Netto, 2014). Englobando todos os demais, o discurso da diversidade cultural tornou-se, nos anos 1990, na expressão de Armand Mattelart (2005: p. 133), "um novo ordenamento mundial". No seu interior, um dos encaixes mais perfeitos é dado pelas noções de "diversidade cultural", "culturas populares" e "comunidade". A ideia de "cultura popular" tem sido associada, desde a sua criação, no Século XIX, a 
várias expressões, sobretudo a de tradição, passado, campo etc. No cenário contemporâneo, ela se renova, sendo compreendida como "patrimônio imaterial", um conjunto amplo de formas de ser e de viver relacionado, desde a ECO 92, à preservação da biodiversidade (Mattelart, 2005). Agora narradas no plural, as "culturas populares" tornam-se praticamente sinônimo de "diversidade cultural".

Esta maneira suave de compreender o mundo das classes populares é muito mais geral. Há algumas décadas, é notório que a palavra "comunidade" substituiu outros tidos como pejorativos, como favela, morro etc. Os exemplos são muitos, mas basta lembrar que a Favela da Rocinha, no Rio de Janeiro, tornou-se a "Comunidade da Rocinha"; o Morro do Vidigal, palco de terrível chacina, transformou-se na "Comunidade do Vidigal". Não por acaso, mas por razões discutidas ao longo deste texto, ali se desenvolveu um dos mais famosos projetos socioculturais do Brasil, o Afro Reggae (Junior, 2006). A referência às favelas como "comunidades" tem facilitado o trânsito da chamada "cultura da periferia", em suas múltiplas expressões, especialmente o hip hop e o funk, hoje amplamente consumidos por setores das classes médias. Desde então, "comunidade" passou a ser a forma "politicamente correta" para referir-se não apenas às favelas, mas, de forma geral, às populações pobres das periferias das grandes cidades e dos centros decisórios do país.

Outro fator decisivo para o espraiamento do vocábulo "comunidade" - e das ideias que ele evoca - foi o reconhecimento, pelo Art. 68 da Constituição brasileira de 1988, do direito à propriedade definitiva da terra por parte dos "remanescentes das comunidades dos quilombos" que as estivessem ocupando. Esta nova figura jurídica e seus desdobramentos políticos posteriores fizeram emergir uma série de grupos denominados "comunidades quilombolas" dispostos a ver reconhecidos seus direitos fundiários. De "remanescentes de comunidades de quilombos", como diz o texto da lei, os novos quilombolas passaram, imperceptivelmente, a "comunidades remanescentes de quilombos" por uma confusão semântica, proposital ou não, tanto dos movimentos sociais quanto dos textos acadêmicos, provocando no meio uma verdadeira epidemia da noção de "comunidade".

Ao lado dos quilombolas, também passaram a ser tratadas como "comunidades" as chamadas "populações tradicionais", como os grupos indígenas, de pescadores, extrativistas da floresta, os praticantes de religiões afro-brasileiras ou "povos de terreiro" etc. Com a vantagem de substituir expressões de conotação negativa que as identificavam como "atrasadas", ou mesmo "sem história", elas agora atendem pelo nome de "comunidades indígenas", "comunidades ribeirinhas", "étnicas", "religiosas" ou, em conjunto, "comunidades tradicionais". 
Artigos e livros foram publicados; exumados do passado, os até então renegados "estudos de comunidade" voltaram a ser objeto de investigações e debates.

Tentando dar conta de fenômeno de tamanha abrangência, Javier Lifschitz (2011) desenvolveu cuidadoso estudo sobre o que chamou de "neocomunidades". Após percorrer a bibliografia sobre o conceito de "comunidade" nas Ciências Sociais e sobre os "estudos de comunidade" no Brasil, aponta a emergência dessa nova forma de organização social, de natureza diferente das comunidades tradicionais. Para Lifschitz, apesar de mundial, a nova onda comunitarista seria particularmente característica da América Latina, onde o autor destaca os casos do Peru, da Bolívia, da Argentina, da Colômbia e do Brasil. Nestes países, a retomada da "comunidade" estaria vinculada à questão étnica; nos dois primeiros, à problemática indígena; nos três últimos, à identidade negra. $\mathrm{O}$ caso da Colômbia e do Brasil seriam ainda mais próximos, uma vez que o reforço da noção de comunidade teria ocorrido a partir de leis que reconheceram o direito à propriedade fundiária por parte de "comunidades negras", na Colômbia, e de "remanescentes de quilombos", no Brasil. (Lifschitz, 2011: 85)

A análise de Lifschitz esclarece, em particular, como a noção de "comunidade quilombola" se ampliou. Para o autor, a noção jurídica de "remanescentes de quilombos", da Constituição de 1988, seria aplicável apenas "a uns poucos grupos".

Contudo, como a norma não definia com precisão o alcance dessa categoria abriu-se uma brecha para a disputa política em torno da "ressemantização" do termo "quilombo"... De seu original sentido histórico como local de fuga, o quilombo passou a ser ressignificado como "remanescente de quilombo", indicando a ascendência de comunidades negras com relação ao passado escravocrata, e logo, como "comunidades quilombolas", autodefinidas como tal e com direito à propriedade coletiva das terras nas quais habitavam e trabalhavam. (Lifschitz, 2011: 86)

Com o início do governo do presidente Luís Inácio Lula da Silva, é criado o Programa Brasil Quilombola, envolvendo 17 ministérios e cinco secretarias especiais, as quais, em conjunto com a Política Nacional de Desenvolvimento Sustentável dos Povos e Comunidades Tradicionais definem a "orientação de políticas públicas específicas, nas áreas de educação, habitação, saúde e infraestrutura para as comunidades quilombolas". Ao final do mandato do presidente Lula, havia 3.250 "comunidades quilombolas" reconhecidas em todo o país, segundo dados da Seppir (Lifschitz, 2011: 87). De qualquer maneira, percebe-se 
que neste primeiro e já bastante amplo conjunto de significações, "comunidade" refere-se sempre às classes populares.

Entretanto, a noção de "comunidade" ampliou sua dubiedade, deslizando sorrateiramente para as outras classes sociais. No fim dos anos 2000 , de forma aparentemente inofensiva, a palavra podia ser encontrada, por exemplo, na seção "Comunidade" do Bourbon News, boletim informativo de luxuoso shopping center na Zona Oeste da capital paulista. A notícia "Valorizando a vizinhança" alegava:

A chegada do Bourbon Shopping Pompéia trará benefícios não somente aos frequentadores de seu espaço interno. A comunidade local também já ganhou com as mudanças geradas pelo empreendimento, relevantes para o conforto e segurança da região. (Bourbon News, 2009, grifo meu).

Percebe-se claramente que o vocábulo "comunidade" é muito mais eficiente do que bairro ou qualquer outro para convencer o leitor sobre os supostos benefícios trazidos pelo shopping. Outro caso bastante esclarecedor é o da Associação dos Criadores de Cavalo da Raça Mangalarga. Formada por ricos fazendeiros, nos seus informativos impressos e em postagens na internet, o grupo se autodenomina "Comunidade Mangalarga".

O fato é que o vocábulo passou a circular independentemente de qualquer contexto social, banalizando-se o seu uso em expressões velhas e novas, como "comunidade judaica", "comunidade europeia", "comunidade gay", "comunidade surda", "comunidade científica", "comunidade acadêmica", "comunidade puquiana", "comunidade psicanalítica", "comunidades terapêuticas", "comunidades carentes", "comunidades de baixa renda" e assim ad infinitum. Ouve-se falar constantemente em "medicina comunitária", "trabalho comunitário", "serviços comunitários" e até mesmo em "polícia comunitária”. Curiosamente, no momento em que o mundo parece dilacerado por disputas políticas, conflitos étnicos, formas perversas de exploração do trabalho, tem-se a impressão de que tudo virou "comunidade" e que os "vínculos comunitários" estão a se espalhar por toda a parte.

Todos falam em "comunidade". O termo incorporou-se definitivamente ao léxico do Estado, em todos os níveis governamentais, em particular, no setor das chamadas "políticas públicas". Ele é essencial ao discurso das ONGs em seu papel de intermediários, envolvidos com a captação de recursos para projetos socioculturais. É utilizado, também, por instituições privadas, sobretudo fundações e institutos, justificando a destinação de verbas para iniciativas de 
alegado caráter social, cultural, educacional. Finalmente, voltou a pautar o pensamento acadêmico na grande área das Ciências Humanas.

De acordo com o Banco de Dissertações e Teses da Capes (2016), as áreas de concentração com o maior número de trabalhos sobre "comunidade" são, por ordem, a de Educação, com 568 títulos, seguida pela de Ecologia, com 235, e a de Sociologia, com 68. Em $4^{\circ}$. e $5^{\circ}$. lugares aparecem as áreas de Saúde da Comunidade, com 67, e Saúde Coletiva, com 66, as quais somadas totalizariam 133 trabalhos, superando a Sociologia. O destaque do conceito de "comunidade" nas três primeiras áreas é compreensível, sobretudo na de educação. Como veremos melhor, a reabilitação política da noção de comunidade nas últimas décadas do Século XX passou pelos setores educacionais ligados à universidade. ${ }^{2}$

Mas, após essas três, a área que mais produziu trabalhos sobre o tema da "comunidade" foi a Sociologia. A um preço bastante alto. Ao falar de "comunidade", as Ciências Sociais, como diria Pierre Bourdieu (2003), dão por suposta a sua existência. Com raras exceções, nas dissertações e teses da área, a noção de "comunidade" empregada é a mesma das práticas sociais, contrabandeando para o raciocínio sociológico uma série de conotações já agregadas historicamente ao termo, bem como outras que lhe são atribuídas nas circunstâncias atuais em que se assiste ao crescente aumento da desigualdade social em todo o mundo eà precarização das condições de trabalho. Desta forma, o pensamento acadêmico acaba por ratificar conceitualmente a noção idílica de "comunidade" e/ou sua utilização como mecanismo de gestão de populações pobres das periferias das metrópoles dos países pobres.

Assim, o objetivo do texto é mostrar, por meio de fontes bibliográficas sobre o conceito, pesquisas recentes sobre questões correlatas e trabalho etnográfico próprio junto a grupos e instituições envolvidas com a recriação de "cultura popular" na cidade de São Paulo, como a reativação da noção de comunidade, a partir do fim do Século XX, tem uma dupla face. De um lado, como em outros períodos da História, tem um aspecto romântico, utópico e mesmo mítico; de outro, constitui-se em ideologia conservadora, categoria essencial à percepção do espaço social na era da diversidade cultural capaz de operacionalizar relações de poder, de apropriação da cultura do outro e de exploração do trabalho das classes populares.

2 Em algumas áreas do conhecimento, a noção de comunidade deu origem, a partir dos anos 1980, à renovação de disciplinas, como "Desenvolvimento de Comunidade", no Serviço Social, às subáreas, como Psicologia Social Comunitária, Saúde da Comunidade, entre outras. (Wanderley, 1993; Sawaia, 2007). 


\section{0 retorno da "comunidade" na virada para o terceiro milênio}

Nas últimas décadas do Século XX, de forma tão inesperada quanto o retorno da "comunidade", assistiu-se à ampla revalorização das práticas culturais de origem tradicional e popular. Fenômeno de caráter mundial e ancorado no discurso da diversidade cultural, uma de suas manifestações foi a formação, nas metrópoles, de grupos de jovens de classe média interessados em pesquisar e praticar expressões oriundas desse universo cultural. A observação desses grupos na cidade de São Paulo (Mira, 2016) revelou que as ideias de "tradição", "cultura popular" e "comunidade" estão interligadas. Indicou também que circula entre os integrantes desses grupos, aos quais denominamos "recriadores", vários significados do vocábulo "comunidade".

Quando se está minimamente distante do centro da metrópole, "comunidade" designa a localidade, a circunvizinhança em que se situa o grupo. Por exemplo, Leandro Moraes (2007), responsável pela percussão do Ilê Aláfia, grupo recriador de maracatu, afirmou que o seu trabalho era "100\% social com as comunidades do Jabaquara, Vila Clara e região". Nos grupos mais próximos do centro, não se ouve a palavra como referência ao bairro ou à região. Em contrapartida, "comunidade" é invariavelmente utilizado para designar os artistas populares considerados tradicionais, em sua grande maioria, moradores de bairros ou municípios periféricos da capital paulista ou de cidades do interior do estado. O depoimento de Paulo Dias (2005), diretor da ONG Associação Cultural Cachuera! é esclarecedor:

Nós percebemos, Andréia, Manzatti e eu, que essas manifestações musicais eram rurais. Pensamos: Oba! Vamos para a roça, curtir a natureza e [...] só fomos a periferias, cidades industriais, favelas, bairros pobres, não tinha roça. Arturos é uma exceção porque tem um pedacinho de terra em Contagem, mas quase todos trabalham na indústria para sobreviver.

Eu vou para Guaratinguetá, gravar o jongo, eu não vou para Guaratinguetá, eu vou para Tamandaré, que é fora de Guaratinguetá. Eu vou pra Belo Horizonte, gravar o candombe, eu vou para Jatobá, que é um bairro periférico. Você nunca vai na cidade mesmo, o que reflete a condição social dos

3 Utilizo o termo "recriadores" para me referir aos grupos envolvidos com pesquisa e prática de cultura popular tradicional sem vínculo com a tradição familiar. Emprego o conceito de "cultura popular tradicional" para me referir ao conjunto de práticas às quais se convencionou denominar "folclore" ou "cultura popular". Por vezes, uso a expressão "cultura popular" com o mesmo sentido. 
atuais produtores da cultura popular tradicional. São populações com passado rural recente que se deslocaram para as cidades, buscando melhores condições de vida. Porém, não se fixam nas cidades, se fixam sempre nas periferias, nos morros, nas baixadas, nas cidades industriais, onde eles trabalham. Essa é a realidade dos produtores da cultura popular tradicional na atualidade, as periferias urbanas (Mira, 2009).

A “Comunidade dos Arturos", mencionada pelo pesquisador de cultura popular Paulo Dias, é uma família extensa que vive em Contagem, município da Grande Belo Horizonte, descendente de um ancestral comum, de nome Artur. Eles são congadeiros que fazem a festa de Na. Sra. do Rosário, todos os anos, no mês de outubro, a qual se tornou verdadeira Meca dos grupos urbanos interessados em cultura popular tradicional. Os jongueiros de que fala Paulo Dias também são denominados "Comunidade de Tamandaré". Ao serem redescobertas, mais valorizadas e conhecidas, nos anos 1990, as práticas culturais desses artistas populares passaram a transitar por segmentos intelectualizados das classes médias, realizando-se praticamente à margem da cidade onde se situam. As festas e encontros de jongueiros de Tamandaré, por exemplo, incorporam os praticantes do bairro, os apreciadores do jongo vindos de outras classes e localidades, mas, do outro lado da Rodovia Dutra, a cidade de Guaratinguetá não toma conhecimento. Neste ponto, a ideia de localidade já não define "comunidade", mas o conjunto amplo dos praticantes desta expressão cultural, denominado "Comunidade do Jongo". Neste mesmo sentido, pode-se mencionar a "Comunidade do Samba" e assim por diante. A "comunidade", neste caso, baseia-se no sentimento de pertencimento a determinada coletividade. Porém, não se trata de "comunidades virtuais". Embora os grupos tradicionais e os recriadores tenham suas redes sociais na internet, seu diferencial em relação a outros grupos urbanos é justamente a importância conferida ao momento presencial, ao encontro face a face, sobretudo, com os "mestres da tradição".

É o que acontece com os grupos tradicionais de maracatu do baque virado. Seus praticantes vivem na periferia de Recife ou cidades vizinhas e, da mesma maneira, são chamados pelos jovens paulistanos que recriam sua expressão de "comunidades". Como no caso da congada, do jongo e outras expressões, a ideia de "comunidade" é legitimada pela sua real ou suposta relação com a tradição, a ancestralidade, o enraizamento etc. Para os recriadores de "cultura popular", as "comunidades" são, antes de tudo, portadoras e guardiãs da "tradição", como explicitou Henrique Barros, líder do Caracaxá, grupo recriador de maracatu: 
[...] o Caracaxá tem uma preocupação de valorizar essas comunidades que... a gente entende como sendo tradicional e que preservam a manifestação há 200 anos atrás, mais de 200 anos. Então essas comunidades... são, claro, para todo mundo do Caracaxá... a referência, que a gente se espelha, que a gente vai lá todo ano pesquisar, estar um pouco mais próximos dessas pessoas, dessas comunidades (Mira, 2009).

É também habitual que os praticantes considerados tradicionais sejam denominados "comunidades de referência". Cada grupo recriador pode adotar uma "comunidade" para "se espelhar", como é o caso da relação entre o Caracaxá de São Paulo e o Maracatu Nação Porto Rico de Recife. Por vezes, grupos inteiros vão a Recife para conviver com a "comunidade". Representantes maiores de suas "comunidades", os "mestres da tradição", em geral, os mais velhos, encantam os jovens paulistanos:

[...] eu vejo aqueles senhores, sabe, de chinelão havaiana e aquela simplicidade dançando congada, reisado, mantendo a tradição, é muito lindo, é uma simplicidade muito desconcertante... não precisa de muito pra ser feliz, você vê que essas pessoas são felizes naquela vida, na delas e é passado de pai pra filho, de geração pra geração, é uma coisa que sobrevive, é muito bonito, não precisa de luxo, não ostenta nada, é uma coisa que nasce com eles, contagia... (Norberto, 1999).

Os mais velhos personificam, como ninguém, a natureza inclusiva da vida comunitária para os jovens paulistanos interessados em cultura popular tradicional. O contato com os artistas populares os emocionou e despertou neles o desejo de viver em comunidade, de ser comunidade, como relatou Paulo Dias, do Grupo Cachuera!:

[...] a carga emocional que isso passa, muitas vezes, você 'tava lá gravando e as lágrimas escorrendo [...] te sacode, te tira do chão e a gente tão carente de rituais na nossa vida, as manifestações onde participa[m] o velhinho, a criança, o adolescente, todo mundo tá junto, manifestações em que todos produzem arte, não tem o produtor e os consumidores de arte, um show de rock em que tem lá um cara tocando guitarra e todo mundo sacudindo [...] quer dizer, não tem uma relação de produtor-consumidor, tem uma relação de produção comunitária em que todos estão incluídos... Quantas e quantas vezes eu fiz rituais de profunda gravidade religiosa com um bêbado ali falando um monte de abobrinha e ninguém vai lá tirar o cara. Quantas e 
quantas vezes eu vi isso. Vi pessoas [...] excepcionais, por exemplo, fazendo trabalhos de preparação da festa e considerados como pessoas da comunidade, como iguais. Isso foram lições de vida também que são muito importantes pra gente. Que até naqueles velhos tempos do Cachuera! a gente tentava trazer lá pro terreiro, fazer o nosso saravá, que era quase que uma encenação de um modo de vida desejado, através dos rituais (Mira, 2009, grifos meus). ${ }^{4}$

De fato, a reativação da ideia de comunidade, na virada para o terceiro milênio, tem esse aspecto mítico, de eterno retorno ao paraíso perdido da humanidade. Como resumiu Judith Kapferer:

A busca por um sentimento amigável, o sonho da comunidade, de sentimentos compartilhados e entendimento mútuo e a confortável familiaridade das relações face a face refere-se a uma idade de ouro dos homens. Tida por garantida ou negada pela perda ou exílio, o calor, a solidariedade e amizade da família, parentes e vizinhos, o senso de pertencimento e identificação têm sido, há muito, o baluarte contra os terrores da solidão, alienação e desespero e preenchido a imaginação humana tanto de comunidade quanto sociedade (Kapferer, 1994: 58).

Para falar apenas do Século XX, o mito da "comunidade" fez parte do imaginário da contracultura e do movimento hippie, cujos ecos ressoam até hoje. Viver em comunidade era uma forma de transgressão das normas instituídas e alternativa à sociedade de consumo. Florescendo sobretudo entre os jovens, os projetos e utopias comunitárias vão e voltam. Na Introdução à seleção de textos sobre comunidade de autoria, de Martin Buber (1987), os organizadores explicam que uma das razões que os levou a fazê-la foi a convicção de que

há pelo mundo afora um grande número de pessoas que ainda buscam ativamente uma forma de vida social alternativa, capaz não só de resolver os grandes problemas a nível da organização política global das sociedades, mas também de dar uma nova substância à vida, através da modificação substancial das relações a nível interpessoal (Dascal; Zimmermann, 1987:10).

Buber (1987) discordava de autores que o antecederam para os quais a "comunidade" teria sido uma forma de convívio social historicamente superada gramados da Cidade Universitária/ USP, nos anos 1990.
} 
pela "sociedade". O autor apoiava-se na distinção elaborada por ele mesmo entre "antiga" e "nova comunidade". A antiga corresponderia à comunidade formada por "laços naturais". Mas, novas comunidades poderiam ser criadas com base em relações de livre escolha dos indivíduos. Pensador judeu, religioso e humanista que passou pelo nazismo e o fascismo, por duas guerras mundiais e que conheceu a vida nos kibutz, Buber foi um defensor da vida em comunidade como a forma que tornaria possível a convivência pacífica e tolerante entre os homens. Boa parte de seus textos sobre o tema são conferências inflamadas que opõem a comunidade à massa, ao Estado etc. É bem possível que, se fôssemos percorrer os Séculos XIX e XX com cuidado, encontraríamos, para além dos "tempos quentes" em que o mito da comunidade vem à tona, sua constante reiteração na história cotidiana, como forma privilegiada de crítica da modernidade.

Como já observara Georg Simmel (1977), no início do Século XX, uma característica marcante do complexo processo constitutivo do mundo moderno é a despersonalização das relações sociais, um dos efeitos da emergência da economia monetária. Servindo de mediador entre todas as coisas, o dinheiro diminui, até eliminar por completo, a importância da pessoa com quem se troca. Antes dele, Marx e Engels perceberam com clareza o potencial de desagregação do capitalismo ao afirmar no Manifesto do Partido Comunista, de 1848, que "tudo o que é sólido desmancha no ar". No fim do Século XX, torna-se evidente a ruptura com a tradição - embora convivamos hoje com inúmeras tradições -, com um conjunto de princípios que regiam a construção da memória e da identidade, pessoal e coletiva. Isto significa o ingresso num mundo repleto de possibilidades, mas também de incertezas. Autores de diversas tendências cunharam expressões para definir o solo cada vez mais instável da modernidade, como "desencaixe" ou "destradicionalização" (Giddens, 1991; 1997), "sociedade de risco" (Beck, 1999), "deriva” (Sennett, 1999), "modernidade líquida" (Bauman, 1999), entre outras.

É bastante plausível, portanto, a ideia de Zygmunt Bauman (2003) de que a voga da "comunidade" esteja ligada à "busca de segurança no mundo atual". Porém, para o autor, o comunitarismo do terceiro milênio não é o mesmo do passado, e o tipo de laço que se estabelece entre os indivíduos reunidos em "comunidade" depende do lugar que ocupam no espaço social. $\mathrm{O}$ autor divide o mundo contemporâneo em duas grandes classes, a dos indivíduos de facto e a dos indivíduos de jure. Os primeiros, herdeiros de uma classe privilegiada que, desde o início do capitalismo, podia aliar a liberdade individual, admitida no mundo moderno, à segurança de pertencer a um agrupamento, buscam formar com os outros indivíduos ou grupos uma "comunidade estética", ao passo que a 
maioria das pessoas, que continua e, cada vez mais, vive num mundo inseguro e precário quanto à sua sobrevivência, procura uma "comunidade ética".

Os "bem-sucedidos" ou a "elite global", como ele também denomina os privilegiados, podem ter necessidade de se sentir pertencentes a um grupo de pessoas que faz as mesmas opções. Este pertencimento lhes dá segurança sobre suas escolhas, o que não teriam se as fizessem ou pensassem estar fazendo sozinhos. É a relação típica que se estabelece entre os fãs e um determinado ídolo. Trata-se de um tipo de "comunidade" que estabelece vínculos emocionais com outras pessoas sem o ônus de um relacionamento pessoal. A qualquer momento, o fã pode se evadir da relação com seu ídolo. Como as tribos urbanas, os grupos de estilo de vida, outros bons exemplos, as fronteiras deste tipo de "comunidade" são permeáveis e flexíveis. Já a "comunidade ética" seria buscada por aqueles que são indivíduos apenas perante a lei, mas que não têm como, de fato, exercer sua individualidade. Neste segundo tipo de "comunidade", o que se estabelece são vínculos sólidos, que implicam compromisso, responsabilidade para com os demais. As regras são mais rígidas, as fronteiras mais fortalecidas, mas, em compensação, o nível de segurança pessoal aumenta porque o grupo controla, mas também ampara "os seus".

Tomados como dois tipos ideais, no sentido weberiano, os laços de sociabilidade apontados por Bauman explicam, ao menos em parte, as práticas e concepções dos grupos recriadores de culturas populares sobre o tema da "comunidade". Ao se deparar com os artistas populares, eles acreditaram, ao menos em parte, ter reencontrado a vida em comunidade. Viveram o sonho da vida comunitária. Mas não conseguiram ser uma "comunidade ética", como sintetizou Paulo Dias:

Ética? Nós estamos observando, curtindo e adorando. Eu passei um domingo maravilhoso com o pessoal de Tamandaré com churrasco, interagindo absurdamente como se eu fosse da comunidade. Eu sou muito bem aceito lá, a gente que ficou lá, o Daniel, o Claudião e o Binho, ficamos lá, foi uma delícia. Mas depois eu fui para minha casa em Pinheiros com meu carrão e eles ficaram lá com a pobreza deles (Mira, 2009).

Nenhum grupo envolvido com pesquisa e recriação de cultura popular tradicional em São Paulo assumiu os compromissos que uma "comunidade ética" implicaria. No entanto, pode-se afirmar que formaram entre si e com os artistas populares "comunidades estéticas", no sentido de compartilharem com eles o gosto pelo repertório da cultura popular tradicional. Jamais poderiam adotar os 
mesmos modos de vida. Separados dos artistas populares por barreiras de classe social insuperáveis, os jovens paulistanos dos bairros dotados de "nobreza cultural" (Bourdieu, 1988), valorizam os encontros com as "comunidades", intermediam suas apresentações para novos públicos, pleiteiam a devida recompensa financeira para sua produção, postulam seu protagonismo nas políticas públicas de cultura, mas não podem resgatá-los de sua condição social, nem abrir mão da sua vida para viver com eles e como eles.

\section{Comunidade e sociedade na tradição sociológica}

A oposição entre os conceitos de "comunidade" e "sociedade" como instrumento de compreensão da vida rural ou tradicional em contraste com a urbana ou moderna, aplicada de forma rígida, já foi objeto de crítica no âmbito das Ciências Sociais contemporâneas. Entretanto, quando a noção se esgarça a ponto de se aplicar aos mais diferentes grupos ou formas de vida social, é hora de retomar a tradição sociológica. Ela começa com Ferdinand Tönnies (1979). O sociólogo alemão, indiscutivelmente, foi quem formulou as noções clássicas e opostas entre este conceito e o de "sociedade". O conceito de "comunidade" é o que busca apreender a predominância de relações pessoais e afetivas em oposição à racionalidade ou o formalismo vigente na vida moderna, ou seja, "em sociedade". O autor estabeleceu a célebre oposição entre Gemeinschaft e Gesellschaft e, desde então, sua fórmula é, quase sempre, o ponto de partida de todas as outras. De acordo com Robert Nisbet (1977: 105), o primeiro conceito pode ser facilmente traduzido por "comunidade". Porém, o segundo é de mais difícil tradução. Na maioria das vezes, é entendido como "sociedade", mas, pode também ser interpretado como "associação". O importante é ter em mente o que caracteriza cada um dos tipos criados pelo teórico alemão.

Para Tönnies, a comunidade tem por base a vida natural. Por isso, as relações familiares seriam sua forma mais típica, seguidas pela vizinhança e pela amizade, ou seja, as comunidades de sangue, de lugar e de pensamento. Em todas elas, no entanto, "[...] as vontades individuais se orientam e valem mutuamente para que a relação possa apresentar-se como um equilíbrio de forças". O poder seria exercido sob a forma de autoridade, ou seja, "em benefício do subordinado" (Tönnies, 1979: 37-38, tradução livre). Pode haver e, de fato há, desigualdades entre as pessoas, as quais, porém, não podem passar de "certos limites", sob pena de dissolução "da comunidade enquanto unidade de seres desiguais" (Tönnies, 1979: 45, tradução livre). Ao "sentimento recíproco, obrigatório, como vontade peculiar de uma comunidade", Tönnies dá o nome de consenso 
(Verständnis), afirmando que ele "representa a força particular e a propensão social que mantém unidos os seres humanos como membros de uma totalidade" (Tönnies, 1979: 45, tradução livre). As decorrências desse tipo de organização social seriam as relações estreitas, "o conhecimento íntimo, a comunhão de ideias, donde a vontade comum, a harmonia e a propriedade comunal”, a qual assumiu historicamente as mais diferentes formas, notadamente, a propriedade senhorial ou feudal (Tönnies, 1979: 45-63, tradução livre). Esta totalidade social teria sido substituída, segundo o autor, pela "sociedade" ou "associação", tipo característico do mundo capitalista, industrializado, mercantilizado e urbano. Seu fundamento não seria mais a "natureza das coisas". Não existindo uma unidade dada a priori, os indivíduos, isolados uns dos outros, criariam laços "artificiais" baseados em interesses racionais, notadamente de ordem econômica, mas, também, sociais, políticos etc. Esses laços teriam caráter impessoal, tendendo a gerar "certa tensão com respeito aos demais [...] sendo a intrusão na esfera própria [...] considerada um ato hostil” (Tönnies, 1979: 67, tradução livre). Em suma, a sociedade ou associação, nas palavras do criador da tipologia, é a

[...] construção artificial de um amálgama de seres humanos que na superfície se assemelha à Gemeinschaft ou comunidade em que os indivíduos convivem pacificamente. No entanto, na comunidade permanecem unidos apesar de todos os fatores que tendem a separá-los, enquanto que na Gessellschaft permanecem essencialmente separados apesar de todos os fatores tendentes a sua unificação (Tönnies, 1979: 45, tradução livre).

As ideias de Max Weber (1991) alteram a perspectiva da questão. De modo diferente de Tönnies, ao definir comunidade e sociedade, Max Weber não faz diferença entre formações sociais, mas entre tipos de ação social, no caso, entre relação comunitária e relação associativa, repousando o sentido da primeira no sentimento de pertencer ao grupo (semelhante a uma irmandade), e o da segunda no ajuste de interesses (como um clube ou qualquer associação ou sociedade). Como outros conceitos do autor, as duas formas de relação são tipos ideais. Na realidade concreta, suas características se misturam. Porém, o segundo tipo de relação social teria superado historicamente o primeiro, ou seja, os laços comunitários teriam sido dominantes nas sociedades pré-capitalistas ou tradicionais, enquanto que os societários viriam a predominar no capitalismo. Pensando em termos de relação e não de totalidade social, de "laços comunitários", não predominantes, mas possíveis na modernidade capitalista, o suposto 
encontro com "comunidades" por parte dos mediadores culturais envolvidos com artistas populares, torna-se mais plausível do que uma simples miragem.

Foi o que evidenciou Eunice Durham sobre o processo migratório para a cidade de São Paulo: a estrutura da antiga "comunidade rural", ela própria em processo de desagregação acelerado nos anos 1960, não se mantém após a migração para a cidade.

O migrante não vive mais em um universo relativamente fechado; as atividades se dissociam, rompe-se a teia de significados inter-relacionados que abrangia a quase totalidade dos modos de vida. Permanecem apenas a família e os parentes, como grupos de relações pessoais que orientam a participação no novo universo sociocultural e dentro dos quais se elaboram as novas representações (Durham, 1973: 14).

A pesquisa realizada por Eunice Durham, no início dos anos 1970, apontava que, por um lado, diluía-se na metrópole a comunidade como unidade social, mas, por outro, o êxodo rural não destruía totalmente os laços comunitários, apenas os restringia ao grupo familiar. As relações de parentesco permaneciam importantes na vida urbana em função da precariedade do migrante frente ao trabalho assalariado. Era a estrutura baseada em relações pessoais que assegurava a sobrevivência da mãe que não podia trabalhar, dos que não tinham idade para fazê-lo, do desempregado, do subempregado etc. (Durham, 1973: 191). Assim, concluía a autora, "[...] desaparece a comunidade, tal como existia na vida rural e tendem a se contrapor, com modos diferentes de participação social, a família e o grupo de parentes, de um lado, e a sociedade complexa e diferenciada de outro" (Durham, 1973: 215).

Apesar de grandes mudanças nas periferias das metrópoles, o estudo pioneiro de Eunice Durham permanece válido no que diz respeito à importância da família no modo de vida e de sociabilidade das classes populares. Parece também com a atual conformação dos grupos praticantes de cultura popular tradicional que ocupam as periferias das metrópoles. Esses grupos de artistas populares são formados, em vários casos, por irmãos, primos, cunhados, amigos, vizinhos etc.. Suas festas são feitas na casa de algum parente, da mãe, da tia, de alguém que disponha de um local maior, ou que foi aumentando com o tempo, e se tornou "tradição". De modo diverso da família burguesa, ou pequeno-burguesa, de onde provêm os pesquisadores, as casas são mais abertas, não têm tantas divisórias para criar ambientes de privacidade e intimidade como 
estão acostumados. ${ }^{5}$ Tudo e todos estão mais próximos e mais misturados, pois não há serviçais ou serviços especializados para manter separadas as pessoas "diferentes": não há babás para as crianças ou cuidadores para os mais velhos, clínicas e terapeutas para os alcoólicos e para as pessoas com necessidades especiais. Porém, isto não quer dizer que as classes populares, nem mesmo os grupos de artistas, vivam em comunidade. É bem mais provável que este seja um aspecto romântico da mais nova "redescoberta da cultura popular". Na era da diversidade cultural, a volta da "comunidade" e da aspiração à vida comunitária, um pouco por toda parte do mundo, está relacionada à retomada das ideias de "tradição" e de "cultura popular", como se estivessem todas elas ligadas por um mesmo fio semântico.

Como assegura Robert Nisbet (1977:171-181), desde o início do Século XIX, as primeiras críticas ao pensamento iluminista se apresentavam como valorização das tradições do passado. Estas, por sua vez, teriam sido preservadas pelas antigas comunidades, as aldeias medievais, onde vicejavam as culturas locais ou populares. Não por acaso, o que Nisbet denomina "o redescobrimento da comunidade" ocorre na mesma época que Peter Burke (1989) demarca como a da "redescoberta da cultura popular". Em outras palavras, as noções de "comunidade", "tradição", "cultura popular" e "localidade" estão firmemente vinculadas, portanto, desde o início da tradição sociológica. Se, no Século XIX, no auge da crença no progresso e na civilização, a polarização entre tradição e modernidade, comunidade e sociedade, cultura popular e cultura letrada ou científica já se fazia sentir, nos dias atuais, encontra ressonância no mundo todo. Se, no Século XIX, as críticas ao iluminismo tinham caráter conservador (Nisbet, 1977), no fim do Século XX, a crítica à ciência e à razão instrumental leva a nostalgia da vida comunal a assumir as dimensões de um mito. E, como sintetizou Lévi-Strauss, "nada se assemelha mais ao pensamento mítico que a ideologia política” (Lévi-Strauss, 1975: 241).

\section{Comunidade: da reabilitação à mistificação}

Um mito não pode ser definido pelo seu conteúdo, mesmo porque, como ensinou Lévi-Strauss (1975), o que existe são as suas diferentes versões. O mito é uma maneira de pensar, definida, sobretudo, por seu caráter totalizante. $\mathrm{Ou}$ o mito explica tudo ou não explica nada. "Comunidade" parece corresponder ao anseio da sociedade contemporânea de tudo encaixar, de uma forma ou 
de outra, na "terra redonda dos mitos" que tudo incorpora e tudo ressignifica (Lévi-Strauss; Eribon, 2005). Remetendo para lá todos os seus dilemas e todos os seus "esquemas", os indivíduos e grupos elaboram narrativas pessoais e coletivas dotadas de sentido e de alta credibilidade social. Por seu turno, a noção de ideologia não se refere simplesmente ao falseamento da realidade social. Embora seja possível extrair dos textos de Marx a dicotomia entre a aparência da realidade e sua essência, que a investigação social tem a missão de desvendar, também é possível pensar a ideologia como uma espécie de inconsciente de classe, como a sua visão de mundo, como os limites do que lhe é permitido enxergar sem considerar sua própria dissolução.

Do ponto de vista ideológico, uma questão importante a se fazer a respeito do emprego do termo "comunidade" para designar favelas, morros e vilas das periferias urbanas ou populações rurais, como os grupos indígenas, os atuais quilombolas, entre outros, é se estaríamos diante de um processo de "atribuição" ou de "renomeação" (Poutignat; Streiff-Fernart, 1998). Teriam sido os mediadores sociais e culturais a levar a ideia de "comunidade" às classes populares ou a mudança de nome teria ocorrido de forma endógena? A pesquisa realizada por Fernanda Piccolo (2006) na favela Parque Vila Isabel, no Rio de Janeiro, em 2003, demonstra que a palavra "comunidade" substituiu "favela" devido ao seu alto índice de estigmatização. Como lembra a autora, desde o seu surgimento, no fim do Século XIX, "a favela significa carência, desordem e violência" e, embora tenha mudado ao longo do Século XX, não deixou de representar uma "chaga no espaço da cidade contemporânea"; de lugar de "malandros, sambistas e capoeiristas" passou a ser vista como "abrigo de traficantes" (Piccolo, 2006: 331-332). A partir da adoção do termo "comunidade", nas palavras da autora, "[...] é inaugurado um processo de positivação desse espaço e de seus moradores ao mesmo tempo em que o vocábulo 'favela', tanto na sociedade em geral, como no interior da favela, é utilizado designando o que é considerado esteticamente feio, desordeiro, negativo" (Piccolo, 2006: 334). Porém, por meio da etnografia, não foi possível à autora perceber como se deu a identificação entre "favela" e "comunidade".

Contudo, o trabalho de Ana Maria Doimo (1995) demonstra que, em São Paulo, e nas cidades e capitais onde as Comunidades Eclesiais de Base (CEBs) e os movimentos sociais tiveram atuação importante, a história recente da retomada positiva do conceito de "comunidade" pode ser recuperada desde a mediação da igreja católica até o surgimento das ONGs. De acordo com a autora, a igreja católica não teria se limitado a abrigar sob o seu teto os perseguidos pela ditadura, inclusive os movimentos sociais, nem sua atuação teria se restringido ao seu setor progressista. $\mathrm{O}$ investimento da igreja católica teria tido um caráter 
integral e institucional, pós-Concílio Vaticano II, alterando o papel dos leigos, tornando-os mais atuantes na sociedade, de tal modo que eles viriam a formar as comunidades eclesiais de base.

Em seu estudo de base etnográfica no bairro do Morro Grande, Zona Oeste de São Paulo, em meados dos anos 1980, Carmem Cinira Macedo (1986) observa a transição da categoria "paróquia" para a de "comunidade". Naquele momento, a autora registra que, enquanto menor unidade administrativa da igreja católica, a paróquia é um conceito que "se dilui cada vez mais porque está passando a se referir a um determinado conjunto de comunidades eclesiais de base e que, em termos da proposta de CEBs, daquilo que, numa perspectiva teológica se pretende que elas sejam, a 'comunidade' deveria ser a unidade da Igreja" (Macedo, 1986: 84).

A noção de "comunidade" abrangia, então, somente os que frequentavam as reuniões na igreja, cerca de 200 a 250 pessoas, das quais 20 eram considerados líderes, contra 3.200 moradores do bairro, na estimativa da autora. Porém, sabe-se o quanto as CEBs foram importantes na constituição de lideranças para os movimentos sociais na década de 1980. Como indicava a autora:

[...] essa reduzida porcentagem de pessoas não significa, contudo, que se trata de um grupo social pouco relevante. Pelo contrário, a forma intensa pela qual ocorre a participação faz com que tanto a liderança como a CEB tenham um importante papel na vida do bairro e a "comunidade" seja um fenômeno social importante para que se compreenda muito da atual vivência das classes populares e do modo como marcam seu lugar na sociedade brasileira, na atual fase de desenvolvimento urbano-industrial (Macedo, 1986: 84). ${ }^{6}$

A comunidade engendrada pelas CEBs não é a mesma a que se referia Eunice Durham (1973). Não são resquícios da antiga comunidade rural após a transição do migrante para a periferia da cidade. Trata-se de uma associação entre setores das classes populares, membros da igreja católica progressista, na época pautada pela Teologia da Libertação, e intelectuais de esquerda. Com base, sobretudo, no estudo de Doimo (1995), percebe-se que a reabilitação da ideia de comunidade ocorre nas periferias das metrópoles brasileiras no âmbito das CEBs. A autora argumenta que a ideia de comunidade, "[...] de conotação fortemente conservadora, obteve ampla reabilitação [...] associada aos 'novos

6 É importante notar que Carmem Cinira Macedo (1986), provavelmente, percebendo que já não se tratava da mesma realidade social coberta pelo conceito de "comunidade" na tradição socioantropológica, grafa-o entre parênteses ao referir-se às CEBs. 
movimentos sociais"' (Doimo, 1995: 89). Para enfatizar a importância da igreja, a autora lembra que, segundo Pierre Sanchis, comunidade é "a palavra que perpassa o discurso da Igreja em todos os tempos", e, talvez, seu principal patrimônio a ser preservado (Sanchis apud Doimo, 1995: 90). Analisando a volumosa documentação produzida pelos envolvidos nos movimentos populares no período, a autora demonstra que a maior porcentagem desses documentos era de responsabilidade de membros da hierarquia da igreja católica, de agentes de suas pastorais ou de líderes das comunidades eclesiais de base. Tão próximos e de tal forma apoiados nas CEBs estavam os movimentos populares que a autora os denominará "comunidades reivindicantes" (Doimo, 1995: 74).

Essas "comunidades reivindicantes", ou seja, os movimentos de moradia, saúde, transporte coletivo, custo de vida, emprego etc., seriam o resultado de um conjunto de "conexões ativas" que explicariam, segundo a autora, a regularidade das ações dispersas dos movimentos populares entre 1975 e 1990.

[...] a despeito do caráter diverso, fragmentado e localizado, próprio das ações diretas, eles apresentaram certos níveis de regularidade, homogeneidade e continuidade, convergindo para um grande ciclo reivindicativo, cujas conexões ativas são evidentes: a igreja católica, agrupamentos de esquerda e organizações não governamentais, em geral abrigando intelectuais e profissionais empenhados na "causa popular" (Doimo, 1995: 95).

Dentre os intelectuais e militantes de esquerda, a autora considera relevante a ação dos egressos da luta armada e dos expulsos das universidades pela ditadura militar. Na qualidade de intelectuais, eles foram importantes por secretar um conjunto de ideias que perpassava todos os discursos, do início dos anos 1970 até meados da década de 1980, norteando as lutas sociais. Este discurso pode ser sintetizado numa frase-slogan, bem lembrada por Doimo (1995: 74): "o povo como sujeito da própria história". As ideias de "povo" e de "participação popular" obtiveram, nesse período, sua expressão mais positiva no pensamento sociológico (Doimo, 1995: 75). Retomando-se as análises de Gramsci, emergiram as críticas à postura paternalista sobre o tema da cultura popular adotada, nos anos 1960, pelos CPCs - Centros Populares de Cultura - recuperando-se, assim, a força expressiva das classes populares. (Doimo, 1995: 79).

Os movimentos sociais atingiram seu auge na primeira metade da década de 1980, reivindicando moradia, saúde, emprego, enfim, condições básicas de sobrevivência, motivo pelo qual a autora não tem dúvida em denominá-los "movimentos populares". Não por acaso, os movimentos populares entraram em 
declínio na segunda metade da década de 1980, exatamente quando as ONGs começaram a crescer. A reformulação pela igreja católica do papel do leigo na sociedade havia feito proliferar, naquele momento, não apenas as CEBs, mas uma série de organismos dedicados à "educação popular", os quais, no início dos anos 1980, assumiram a forma de ONGs e absorveram intelectuais e militantes de esquerda, à exceção dos partidos comunistas (Doimo, 1995: 84). Os intelectuais e militantes de esquerda que haviam sido exilados, segundo a autora, "acabaram no retorno vinculando-se a experiências de 'educação popular', acomodando-se no interior das ONGs então emergentes". O exílio foi para eles um período de "redefinição de posições ideológicas", bem como de estabelecimento de "diversos tipos de ligações e laços de confiança pessoal com as entidades de cooperação internacional de modo a garantir a reintegração profissional, política e social no país" (Landim apud Doimo, 1995: 79).

De acordo com pesquisa citada pela mesma autora e realizada por Rubem Fernandes e Leandro Carneiro durante o I Encontro Internacional de ONGs e Agências da ONU, em agosto de 1991, tendo como amostragem 102 ONGs brasileiras, obteve-se que: $87 \%$ dos dirigentes tinham diploma universitário; $39 \%$ deles com pós-graduação, sendo 1/3 destes em Sociologia (Doimo, 1995: 79-80). Levantou-se ainda que a filiação dos dirigentes nos anos 1970 era a seguinte: $34 \%$ provinham da Teologia da Libertação; $26 \%$ de CEBs ou pastorais; $14 \%$ do revisionismo marxista; $7 \%$ do maoísmo; 5\% do Partidão; $3 \%$ da social-democracia e $3 \%$ do "desbunde" (sexo, drogas e rock'n roll) (Doimo, 1995: 80). Os dados permitem deduzir que a aliança entre a igreja católica, intelectuais e militantes de esquerda, de fato, deram origem a esse agente tão influente na virada do milênio, as organizações não governamentais. Mais precisamente, explica a autora, os movimentos populares formaram redes sociais nas quais os agentes mediadores se cruzaram transversalmente. Essas redes encontraram terreno fértil nas ONGs, as quais se constituíram a partir da interação seletiva entre os agentes (Doimo, 1995: 151-152). Ao longo dos anos 1990,

[...] essas redes sociais se mantiveram e, inclusive, proliferaram através de centenas de pequenos organismos pelo Brasil afora, a maioria, mantidos através de 'projetos', um dispositivo corriqueiro no interior do MP [movimento popular], que encontra sua contraparte em organismos especializados na intermediação ou "de ajuda" (Doimo, 1995: 156).

O círculo parece se fechar. No terceiro milênio, a noção de "comunidade" aparece em série nos chamados "projetos sociais" ou "culturais". Os jovens de 
classe média envolvidos com o repertório da cultura popular tradicional em São Paulo trabalham com esse tipo de projeto. Vários deles atuavam, na primeira década dos anos 2000, em programas como Barracões Culturais da Cidadania, ministrando oficinas de dança, música, percussão etc. (Mira, 2016). O discurso era infalivelmente o mesmo: as práticas culturais apresentavam-se como instrumentos de recuperação da "autoestima", caminho alternativo ao mundo das drogas e da violência, mecanismos de "inclusão social", programas de "geração de renda" para as "comunidades carentes" ou "comunidades de baixa renda" ou, ainda, "em estado de vulnerabilidade". O repertório das "tradições populares" é transformado em "recurso", na expressão de George Yúdice (2004), e passa a integrar o léxico que organiza ações e representações neste universo, do qual faz parte, pelo lado do capital, a ideologia da "responsabilidade social".

Inúmeros "projetos culturais" ostentam a palavra "comunidade" no seu título. O "Dança Comunidade" realizado pelo SESC-SP, sob a direção do bailarino Ivaldo Bertazzo, é um bom exemplo. De acordo com Helena Katz (2006), a parte central do projeto constava de um curso de formação para 42 jovens, de 13 a 28 anos, constituído por "aulas de canto, linguística, inglês, percussão, história da dança, reeducação do movimento, grupos terapêuticos, grupos de reflexão e discussão (coordenados por um psicólogo, um psicopedagogo e um assistente social), e por ensaios coreográficos/ espetáculos (coordenados por quatro ensaiadores)". Em 2006, quando o grupo apresentava o segundo espetáculo, Milágrimas, no SESC Pinheiros, foram lançados também CD, DVD, documentário e livro de autoria de Carmute Campelo, intitulado Tenso equilíbrio na Dança da Sociedade. Nota-se que a tensão é relacionada à "sociedade", enquanto as boas ações e a beleza do espetáculo remetem à "comunidade". A matéria informa ainda que o projeto envolveu 90 pessoas e o seu custo foi de $\mathrm{R} \$ 2.557 .050,00$, sendo mais da metade desse valor captada por meio da Lei Rouanet de Incentivo à Cultura, ou seja, por meio de isenção fiscal obtida pelas empresas Petrobrás (R\$ $800.000,00)$ e Instituto Votorantim $(\mathrm{R} \$ 550.000,00)$ (Katz, 2006). Em boa medida, a "comunidade" dança com o dinheiro da "sociedade".

O uso generalizado da palavra "comunidade" nos projetos culturais, certamente, se deve ao fato de que, mais do que convencer, a ideia tem o poder de comover de antemão aqueles a quem se dirige devido à sua forte conotação afetiva. O documentário Aterro, que aborda a questão da reciclagem, é dedicado "a todas as comunidades que recebem o lixo da sociedade" (Reis, 2011). Punido pela sociedade, o infrator é condenado a "prestar serviços à comunidade". A polarização entre sociedade e comunidade se acirra na entrada do terceiro milênio, sendo o primeiro o seu polo negativo e o segundo, o positivo. Tudo o 
que é considerado ruim e indesejável é, mais uma vez, atribuído à sociedade urbano-industrial, mercantilizada, massificada, poluída, degradada, sem valores, sem referências etc. $\mathrm{O}$ que é bom e desejável pode, assim, relacionar-se à "comunidade".

Lendo a obra de Tönnies, Robert Nisbet percebe que a oposição entre comunidade e sociedade é tão clássica quanto a própria Sociologia. Por meio de suas observações, pode-se compreender melhor porque o conceito de comunidade tornou-se tão aderente à ideologia política do novo milênio. Diz o intérprete de Tönnies:

A Gemeinschaft e seus diversos correlatos tendem a ser "bons": ou seja, podemos dizer de alguém que caiu em más "associações" ou em uma má "sociedade", mas nunca em uma "má comunidade". Todos os estados de ânimo elementares da sociedade que gozam de apreço - o amor, a lealdade, a honra, a amizade etc. - são emanações de Gemeinschaft (Nisbet, 1977: 107, tradução livre).

As ideias de Tönnies ajudam a entender até mesmo como a noção de comunidade contribui para a transformação em arte dos trabalhos produzidos por grupos populares supostamente vivendo nesta forma de organização social.

A Gemeinschaft, na medida em que é capaz de fazê-lo, transforma toda tarefa em uma espécie de arte, lhe dá estilo, dignidade e encanto e uma categoria dentro de sua classe, assinalada como vocação e honra (Tönnies apud Nisbet, 1977: 107, tradução livre).

Como apontou Fernanda Piccolo, a mudança de nome de favela para comunidade tornou-se operação estratégica diante do novo contexto do que poderíamos chamar de sociedade por projetos:

Nesse contexto, a "comunidade" torna-se uma estratégia discursiva para dirimir os conflitos, pois é nela que o Estado, ONGs e outras instituições podem atuar, através dos projetos sociais... É como "comunidade" que a favela ganha espaço e consegue competir por bens políticos (os projetos sociais), econômicos (os financiamentos) e sociais (o prestígio) (Piccolo, 2006: 348-349).

Mais recentemente, os chamados projetos culturais têm ganhado destaque sobre os projetos sociais em geral. Pesquisando as regiões periféricas de São Paulo - Cidade Tiradentes, Itaím Paulista/ Vila Curuçá -, locais incluídos no que denominou "territórios da precariedade", Cibele Rizek identificou a presença e 
a relevância de agentes vinculados a projetos culturais na produção do espaço urbano e na reprodução do chamado "capitalismo flexível"; observou uma espécie de "culturalização" disseminada "entre os territórios periféricos e pelas 'comunidades' das metrópoles paulistanas" (Rizek, 2011: 127, aspas da autora).

Cibele Rizek acredita que os projetos culturais capturam populações que vivem em "situações-limite", transformando-as em seus "públicos-alvo" (Rizek, 2011: 128), despolitizando a vida urbana e eliminando o conflito. Por meio de depoimentos colhidos em campo, a autora demonstra que esses projetos constituem dispositivos geradores de consenso: todos são favoráveis a eles, inclusive os integrantes das supostas "comunidades". A autora identificou também a mesma gramática discursiva: o famigerado resgate da autoestima, a inclusão social, o empreendedorismo. As ONGs, segundo a autora, são tanto gestoras quanto alvo dessas políticas. Elas que surgiram a partir dos movimentos sociais foram penetrando em uma "zona de indiferenciação" (Rizek, 2011: 129) entre práticas e propostas culturais, de um lado, e gestão social, de outro. Em seus diversos formatos, ONG, OS, coletivos artísticos, associações culturais, elas se transformaram em verdadeiros "laboratórios de flexibilidade" (Rizek, 2011: 136), nos quais podem ser flagradas práticas de trabalho associado em cooperativa, trabalho voluntário e mesmo gratuito. Emoldurado pela aura artística e cultural e pelo suposto resgate da vivência comunitária, os projetos culturais fazem parte do que Rizek (2011: 127) denominou "novas formas de gestão da pobreza".

Finalmente, a autora traz elementos que confirmam a hipótese deste artigo ao afirmar que os "discursos e modos de nomeação" correntes entre os agentes dos projetos culturais se naturalizam e se constituem "como uma forma de conhecimento e reconhecimento objetivado daquilo que se nomeia, desdobrando-se em fraseado, conceituações, dimensões teóricas que acabam por ganhar validação da literatura acadêmica, em especial no discurso e na linguagem das ciências sociais" (Rizek, 2011: 137, grifo meu).

Pelo exposto ao longo do texto, a noção de "neocomunidades", cunhada por Javier Lifschitz (2011), parece inapropriada e mesmo contraproducente quando se pretende uma abordagem crítica da realidade contemporânea. Como o próprio autor analisou (2011: 87) e outras pesquisas já demonstraram, para ter acesso aos benefícios concedidos pelas novas políticas públicas ou financiamentos empresariais, obtidos por meio dos projetos culturais, os candidatos têm que acionar símbolos identitários como prova de seu pertencimento a determinada "comunidade", no caso analisado pelo autor, as "comunidades quilombolas". No mais das vezes, já distantes dessas práticas, recorre-se a agentes externos, antropólogos ou outros tipos de pesquisadores, agentes culturais ou de turismo, 
organizados em ONGs ou associações culturais que atuam como mediadores na reconstituição de práticas tradicionais no mundo moderno. Neste contexto argumenta Lifschitz -, os agentes "de fora" não aparecem como desagregadores da comunidade, como nos "estudos de comunidade", mas, ao contrário, como seus reconstrutores. Este momento novo seria o das neocomunidades, definidas como: "processos culturais em que agentes modernos operam nas formas organizativas, materiais e simbólicas de comunidades tradicionais para reconstruir territórios, práticas e saberes a partir de técnicas e epistemes modernas" (Lifschitz, 2011: 102).

Apesar de engenhosa, a ideia soa contraditória. Todas as características que deram origem ao conceito sociológico de comunidade nas Ciências Sociais foram substituídas por seus opostos. Seria de se perguntar, então, por que dar o nome de "neocomunidades" a formas de organização social, que o autor tão bem descreveu e analisou, se elas são, em tudo, o contrário do que sempre se entendeu por comunidade? Não seria melhor denominá-las associações ou sociedades, de acordo com a tradição sociológica? Ou, então, criar um novo conceito, capaz de dar conta da realidade contemporânea, talvez, um correspondente sociológico ao de "arranjo produtivo local", utilizado pelos economistas? Seria mais plausível do que acreditar que estaríamos diante de um processo de "descomoditização" (Lifschitz, 2011: 93), no sentido, segundo o autor, de deslocamento do interesse pelos objetos para o significado atribuído a eles por cada "comunidade". Quando se sabe que essas novas coletividades, seguindo o exemplo das favelas (Freire-Medeiros, 2009), tornaram-se receptoras do chamado "turismo em comunidades quilombolas", fica fácil identificar que a suposta "comunidade" é, ela própria, a nova commodity.

\section{Considerações finais}

O texto procurou abordar, de forma crítica, ainda que panorâmica, a inflação da ideia de "comunidade" na virada para o terceiro milênio. Levantando algumas explicações possíveis para o fenômeno que se situariam, num gradiente, entre o mito ou a utopia até a mistificação e a ideologia, de outro. Sua preocupação central, no entanto, foi indagar sobre as implicações da adoção, muitas vezes, por mera permeabilidade entre os campos acadêmicos, da produção cultural e artística e da militância política dos sentidos do termo comunidade em circulação nos outros campos. Sem uma análise lexicológica e lógica, com base na "tradição sociológica" dos conceitos que fazem parte do seu arcabouço, a Sociologia corre o risco de produzir uma visão distorcida da realidade pelo 
"pré-conceito" no qual baseou sua análise. Mais do que isso, lança-se à tarefa de produzir discursos facilmente capturados pelas injunções do campo das práticas, atuando neles, não por associar a pesquisa científica à luta social, mas de forma não prevista, nem desejada. Há fortes indícios de que o conceito de "comunidade" esteja passando por este momento de desgaste, de crise, exigindo renovação; talvez, apontando a necessidade de elaboração de um novo conceito, para além das "neocomunidades". Como vimos, um simples deslize semântico e/ou sociológico pode nos levar a validar, à nossa revelia, novas formas de gestão da pobreza.

Em outras palavras, o que se evidencia nos exemplos elencados é que o termo "comunidade" passou a ter operacionalidade imediata; é algo pronto para funcionar de acordo com a nova ordem social. Sem ele não seria possível à favela apresentar-se como protagonista de um projeto social. Não seria possível às ONGs e a todos os outros mediadores culturais captar recursos para seus projetos sem o alegado benefício às comunidades. Da mesma maneira, a ideia de comunidade tornou-se imprescindível para a construção de inúmeros programas de políticas públicas e de investimentos privados em marketing social e cultural.

Atualmente, pode-se mesmo falar em um campo dos "projetos sociais", no sentido bourdieusiano do termo. Neste campo se articulam quatro agentes principais: os órgãos governamentais, os empresários, as ONGs como intermediárias, e as "comunidades". Já se formaram associações, como a Abong; há instâncias de consagração, como o Prêmio Top Social de Marketing, entregue todos os anos às melhores iniciativas empresariais na área social. As áreas de educação, saúde, ecologia estão sempre entre as que recebem mais apoio, o que está relacionado, sem dúvida, à forte presença do tema da "comunidade" nos seus debates. A própria "comunidade", ou seja, o público-alvo dos projetos sociais e culturais, por meio de suas lideranças, aprendeu a se articular para captar recursos provenientes de editais governamentais ou iniciativas privadas. Neste sentido, mesmo abrindo mão de purismos conceituais, o atual sentido de "comunidade" parece muito mais próximo do conceito de "sociedade" ou "associação" do que de qualquer concepção dos laços comunitários que as Ciências Sociais já tenham adotado ao longo de sua tradição teórica.

\section{Referências}

ALVES, Elder P. M. A economia simbólica da cultura popular sertanejo-nordestina. Maceió: Edufal, 2011.

BAUMAN, Zygmunt. Modernidade líquida. Rio de Janeiro: Zahar, 1999. 
. Comunidade: a busca por segurança no mundo atual. Rio de Janeiro: Zahar, 2003. BECK, ULRICH. Sociedade de risco: rumo a uma outra modernidade. São Paulo: Editora 34, 2010.

BOURBON NEWS. Informativo do Bourbon Shopping Pompéia. São Paulo, a. 2, n. 4, 2009. BOURDIEU, Pierre. Espaço social e gênese das “classes". In: BOURDIEU, P. O poder simbólico. 6a ed. Rio de Janeiro: Bertrand Brasil, 2003, pp. 133-161.

La distinción: criterios y bases sociales del gusto. Madri: Taurus, 1988.

BUBER, Martin. Sobre comunidade. São Paulo: Perspectiva, 1987.

BURKE, Peter. Cultura Popular na Idade Moderna: Europa, 1500-180o. São Paulo: Companhia das Letras, 1989.

CAPES. Banco de teses e dissertações. Disponível em: <http://bancodeteses.capes.gov.br/ banco-teses>. Acesso em: dez. 2016.

DASCAL, M.; ZIMMERMANN, O. Introdução. In: BUBER, M. Sobre comunidade. São Paulo: Perspectiva, 1987.

DOIMO, Ana Maria. A vez e a voz do popular: movimentos sociais e participação política no Brasil pós-70. Rio de Janeiro: Relume Dumará/ Anpocs, 1995.

DURHAM, Eunice. A caminho da cidade: a vida rural e a migração para São Paulo. São Paulo: Perspectiva, 1973.

FREIRE-MEDEIROS, Bianca. Gringo na laje: produção, circulação e consumo da favela turística. Rio de Janeiro: Editora FGV, 2009.

GIDDENS, Anthony. As consequências da modernidade. São Paulo: Editora da Unesp, 1991.

A vida em uma sociedade pós-tradicional. In: GIDDENS, A.; BECK, U.; LASH, S. Modernização reflexiva: política, tradição e estética na ordem social moderna. São Paulo: Editora da Unesp, 1997.

HABERMAS, Jürgen. Mudança estrutural na esfera pública: investigações quanto a uma categoria da sociedade burguesa. Rio de Janeiro: Tempo Brasileiro, 1984.

JUNIOR, José. Da favela para o mundo: a história do grupo cultural Afro Reggae. Rio de Janeiro: Ediouro, 2006.

KAPFERER, Judith L. The dream of community: folk festivals and ideology in Australia. In: BROWNE, R. B.; MARSDEN, M. T. The cultures of celebration. Bowling Green: Bowling Green University Popular Press, 1994.

KATZ, Helena. Uma tarefa para o educador Bertazzo. In: O Estado de S. Paulo. São Paulo: 06 mar. 2006.

LÉVI-STRAUSS, Claude. A estrutura dos mitos. In: . Antropologia estrutural. Rio de Janeiro: Tempo Brasileiro, 1975.

LÉVI-STRAUSS, Claude; ERIBON, Didier. De perto e de longe. São Paulo: Cosac Naif, 2005 . 
LIFSCHITZ, Javier A. Comunidades tradicionais e neocomunidades. Rio de Janeiro: Contra Capa/ Faperj, 2011.

MACEDO, Carmen Cinira. Tempo de gênesis: o povo das comunidades eclesiais de base. São Paulo: Brasiliense, 1986.

MATTELART, Armand. Diversidade cultural e mundialização. São Paulo: Parábola, 2005. MIRA, Maria Celeste. Entre a beleza do morto e a cultura viva: mediadores da cultura popular na São Paulo da virada do milênio. São Paulo: Intermeios/ Fapesp, 2016. Sociabilidade juvenil e práticas culturais tradicionais na cidade de São Paulo. Sociedade e Estado. v. 24, n. 2, p. 563-597. Brasília, mai-ago, 2009.

NICOLAU NETTO, Michel. O discurso da diversidade e a world music. São Paulo: Annablume/ Fapesp, 2014.

NISBET, Robert. Comunidad. In: NISBET, R. La formación del pensamento sociológico. v. 1. Buenos Aires: Amorrortu, 1977.

NORBERTO, Rita de Cássia. Depoimento [16 dez. 1999]. Entrevistadora: Cynthia Elias Taboada para a pesquisa Cultura tradicional e pós-modernidade: estudo do resgate de danças e folguedos tradicionais na cidade de São Paulo (TABOADA, 2000 - Anexos).

PICCOLO, Fernanda D. A gramática nativa: reflexões sobre as categorias morro, rua, comunidade e favela. In: FRÚGOLI JR., H.; ANDRADE, L. T.; PEIXOTO, F. (Orgs.). As cidades e seus agentes: práticas e representações. Belo Horizonte: PUCMinas; São Paulo: Edusp, 2006.

POUTIGNAT, Philippe; STREIFF-FENART, Jocelyne. Teorias da Etnicidade. São Paulo: Editora da Unesp, 1998.

PITOMBO, Mariela. A diferença como bem universal: a noção de diversidade cultural. In: ALVES, E. P. M. (Org.). Políticas culturais para as culturas populares no Brasil contemporâneo. Maceió: Edufal, 2011.

REIS, Marcelo (dir.) Aterro. Belo Horizonte: Bagulium Loquo Est, 2011, filme documentário, $\mathrm{HD}, 72 \mathrm{~min}$.

RIZEK, Cibele S. Práticas culturais e ações sociais: novas formas de gestão da pobreza. Cadernos PPG-AU/FAUFBA, a. 10, n.1, 2011.

SAWAIA, Bader B. Comunidade: a apropriação de um conceito tão antigo quanto a humanidade. In: CAMPOS, R. H. F. (Org.). Psicologia social comunitária: da solidariedade à autonomia. $13^{\mathrm{a}}$ ed. Petrópolis: Vozes, 2007.

SENNETT, Richard. A corrosão do caráter: as conseqüências pessoais do trabalho no novo capitalismo. Rio de Janeiro: Record, 1999.

SIMMEL, Georg. Estilo de vida. In: SIMMEL, G. Filosofia del dinero. Madri: Instituto de Estudios Políticos, 1977 [1900].

STEIL, Carlos A.; CARVALHO, Isabel C. M. ONGs: Itinerários políticos e identitários. In: GRIMSON, Alejandro (Org.) Cultura y neoliberalismo. Buenos Aires: Clacso, 2007. 
TÖNNIES, Ferdinand. Comunidad y asociacion: el comunismo y el socialismo como formas de vida social. Barcelona: Ediciones Península, 1979 [1887].

WANDERLEY, Mariangela B. Metamorfoses do desenvolvimento de comunidade e suas relações com o serviço social. São Paulo: Cortez, 1993.

WEBER, Max. Relação comunitária e relação associativa. In: WEBER, M. Economia e Sociedade: Fundamentos da sociologia compreensiva. Brasília: Editora UnB, 1991. YÚDICE, George. A conveniência da cultura. Belo Horizonte: Editora UFMG, 2004.

Recebido em 06/12/2016

Aprovado em 20/12/2016

\section{Como citar este artigo:}

MIRA, Maria Celeste. Comunidade: mito e ideologia política na era da diversidade cultural. Contemporânea - Revista de Sociologia da UFSCar, v. 7, n. 1, jan.- jun. 2017, pp. 11-38. 